OECDpublishing

\title{
INNOVATION \\ POLICIES IN THE DIGITAL AGE
}

OECD SCIENCE, TECHNOLOGY AND INNOVATION POLICY PAPERS

November 2018 No. 59 
This paper was approved and declassified by written procedure by the Committee for Scientific and Technological Policy (CSTP) on 2 November 2018 and prepared for publication by the OECD Secretariat.

This publication is a contribution to the OECD Going Digital project, which aims to provide policymakers with the tools they need to help their economies and societies prosper in an increasingly digital and data-driven world.

For more information, visit www.oecd.org/going-digital.

\#GoingDigital

Note to Delegations:

This document is also available on ONE M\&P under the reference code:

DSTI/STP/TIP(2018)5/FINAL

This document, as well as any data and any map included herein, are without prejudice to the status of or sovereignty over any territory, to the delimitation of international frontiers and boundaries and to the name of any territory, city or area.

The statistical data for Israel are supplied by and under the responsibility of the relevant Israeli authorities. The use of such data by the OECD is without prejudice to the status of the Golan Heights, East Jerusalem and Israeli settlements in the West Bank under the terms of international law.

(C) OECD (2018)

You can copy, download or print OECD content for your own use, and you can include excerpts from OECD publications, databases and multimedia products in your own documents, presentations, blogs, websites and teaching materials, provided that suitable acknowledgment of OECD as source and copyright owner is given. All requests for commercial use and translation rights should be submitted to rights@oecd.org. 


\section{Table of contents}

INNOVATION POLICIES IN THE DIGITAL AGE ................................................................ 4

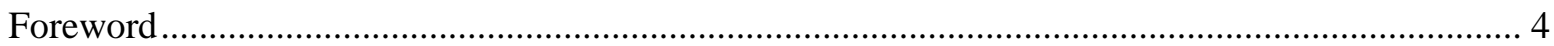

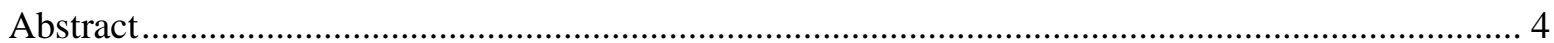

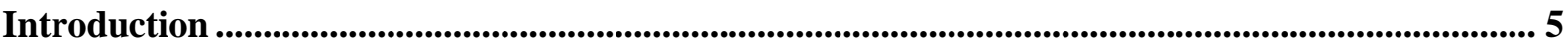

1. Impacts of the digital transformation on handling information and knowledge......................... 10

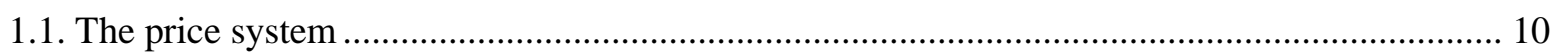

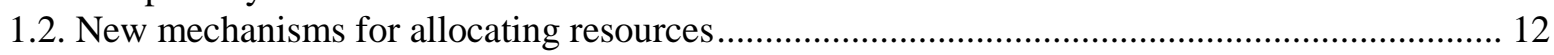

2. Impact of the digital transformation on innovation processes and outcomes............................ 14

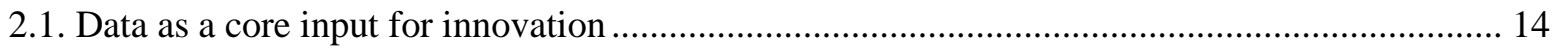

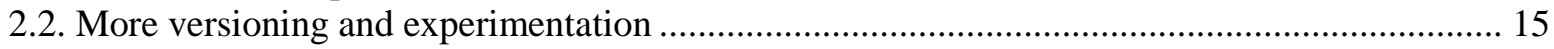

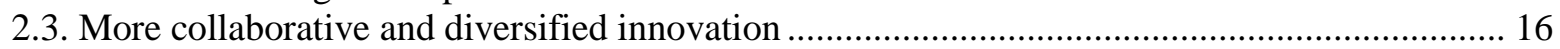

2.4. The blurring frontier between manufacturing and service innovation.................................... 18

2.5. Digital technologies and artificial intelligence as general purpose technologies (GPT) ............ 18

3. Economy-wide effects of digital innovation: Business dynamics, market structures and distributional effects.................................................................................................................................. 19

3.1. Drivers of new business dynamics and market structures ..................................................... 19

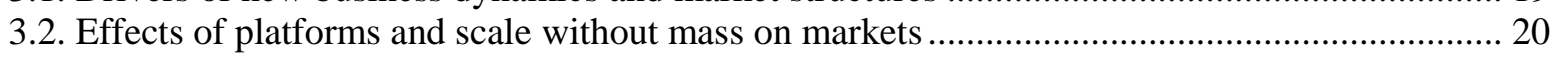

3.3. Distribution of performance and rewards: People and places.................................................... 22

4. Innovation policy changes required in the digital age...................................................................... 23

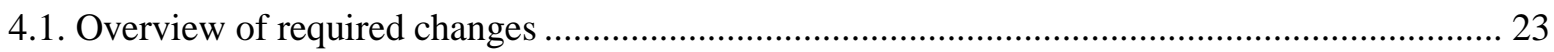

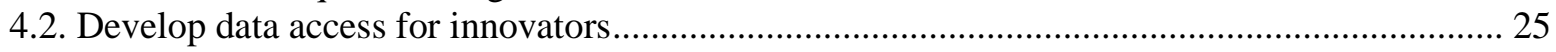

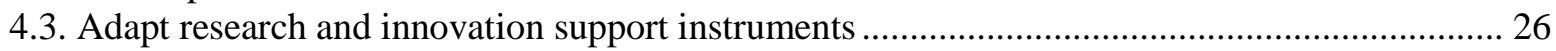

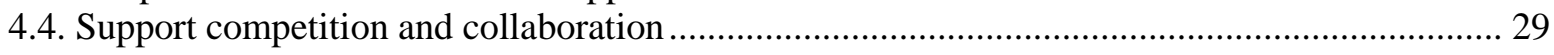

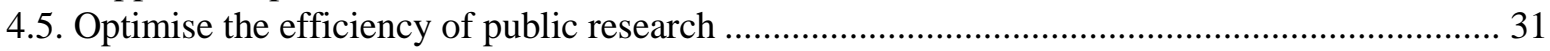

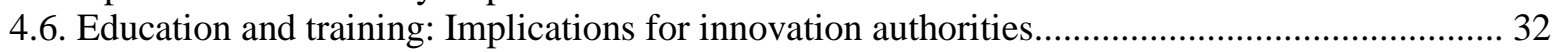

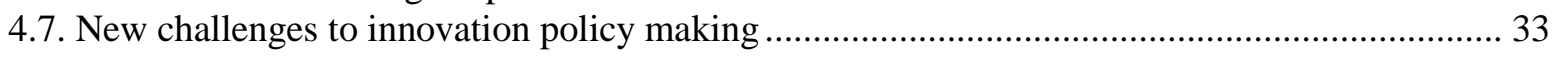

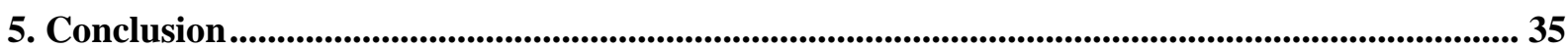

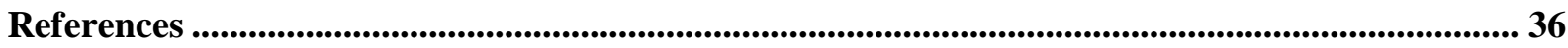

Tables

Table 1. Policy issues and instruments requiring change to be effective in the digital age ................... 8

Table 2. Major changes to the main domains of innovation policies called for by digitalisation ......... 24 


\title{
INNOVATION POLICIES IN THE DIGITAL AGE
}

\author{
Dominique Guellec* and Caroline Paunov*
}

\section{Foreword}

This document explores the effects that digital innovation is having on innovation policies. A product of the digital and open innovation project of the TIP Working Party, it is linked with and contributes to the OECD-wide Going Digital initiative. In particular, it draws from and expands upon the report to the meeting of the OECD Council at Ministerial level, Going Digital in a Multilateral World (OECD, 2018a) and the report Vectors of the Digital Transformation (OECD, forthcoming).

\section{Abstract}

This paper looks at how digitalisation is transforming innovation, and the consequent need for innovation policies to adapt. The paper shows that the digital transformation affects the economics of information and knowledge, in particular pricing and allocation. The reduced costs of producing and handling information and knowledge and the increased fluidity change innovation dynamics. Data have become a core input for innovation. Other changes include more opportunities for versioning; an acceleration in innovation, more experimentation and collaboration; servitisation; and higher risk associated with these general purpose technologies. The digital transformation also has economy-wide effects in terms of business dynamics, market structures and distribution. In view of this transformation, changes to innovation policy are required in the digital age. Innovation policies need to address data access issues; become more agile; promote open science, data sharing and co-operation among innovators; and review competition for innovation and intellectual property policy frameworks.

Keywords: digital innovation, innovation policy, digital technologies, economics of knowledge and information, servitisation, acceleration of innovation, market structures

JEL Codes: O31, O33, L20

Acknowledgements: The authors would like to thank Sandra Planes Satorra for her inputs to this paper. We would also like to thank Erik Brynjolfsson, Luc Soete and the participants of the University of Barcelona Innovation Seminar (2018), JDE Seminar at MIT Sloan (2018), the Symposium "A New Take on Innovation in Canada" (2018), the ENEF 2018 on Firm Automation in the Era of Artificial Intelligence, the SMARTER Conference on Smart Specialization and Territorial Development (2018) and seminar participants at policy discussions in Beijing, Bruxelles, Den Haag, Grenoble, Paris, Tokyo and Utrecht for their valuable comments and suggestions. Detailed feedback from experts and delegates to the OECD Working Party on Innovation and Technology Policy (TIP) and the OECD Committee for Scientific and Technology Policy (CSTP) are gratefully acknowledged.

*OECD 


\section{Introduction}

Most innovations today are new products and processes, enabled by digital technologies or embodied in data and software. These digital innovations are both an outcome and a component of digital technologies, which make it possible to collect, process, manipulate, store and diffuse data (digitalised information and knowledge) automatically, using machines. Those tasks have been performed by humans over time, with increasing but limited support from "technologies" (books, abacus, etc.). The mechanisation of information processing has allowed the performance of these tasks to enter a new era, where it can benefit from technical change. Progress in electronics (Moore's law) and in data science has allowed for a new way of using technologies: information of all types is put in digital form (" 0 " and " 1 ", embodied in electrons), and can be processed, stored and circulated automatically. Advances in artificial intelligence (AI) promise a further acceleration in these processes, facilitating the manipulation of information and knowledge.

These changes driven by the advancement of science and innovation are also themselves drivers of science and innovation. Today digital technologies are essential to the innovation process; most if not all innovations are at least partially digital. This transformation took place first in digital sectors (e.g. software) and has now spread to all sectors, including many tangible sectors, such as the agro-food and automotive sectors (Paunov and PlanesSatorra, forthcoming ${ }_{[3]}$ ). The Internet of Things (IoT) represents the vision that every object and location in the physical world will have network connectivity, allowing them to send and receive data and, consequently, becomes part of the digital world. Innovation processes and outcomes are being transformed precisely because the digital world differs in many dimensions from the physical, tangible world. Changes in innovation are particularly deep because digitalisation changes how knowledge -innovation's key ingredient - is produced and disseminated.

With such broad and deep transformations in innovation under way, it is important to evaluate whether policy support to innovation should adapt, and in what directions. This study focuses on that question. Building on an assessment of the economic mechanisms transformed by digitalisation, the paper presents a framework that characterises the impacts of the digital transformation on innovation processes and outcomes, and the effects of those impacts on business dynamics, market structure, and the distribution of income. Based on this assessment, lessons are drawn for the design of innovation policies. The framework, outlined in, builds on existing evidence of the effects of the digital transformation and specific policy cases.

Several conclusions emerge. Digital technologies have drastically reduced the costs of searching, sharing and analysing data. They have also increased the fluidity of knowledge and data. Once available, digitised knowledge (knowledge put in the form of digital data) and digitised data can be shared instantaneously among any number of actors, no matter the geographic distance or other barriers, and each of those actors have full access to the whole package (OECD, forthcoming).

These changes have affected innovation processes and outcomes in the following ways:

1. New possibilities for handling data have made them core inputs for innovation in all sectors of the economy. The ways data feed into innovations range from using information on consumer behaviour to enabling entirely new services (such as 
transportation services as illustrated by Uber that relies on instantaneous information about demand and supply for transportation services).

2. Innovation has become more collaborative, due to the reduced costs of collaborating and the greater need for interdisciplinary research.

3. Opportunities for launching new products and processes at lower cost using the Internet and relevant platforms facilitate versioning and experimentation of products for differentiated customers. Innovation can also be more frequent: in the automotive industry, while new car models are launched once a year, software updates (which are innovations and modify the models concerned) are issued at a high frequency, e.g. by Tesla Motors. These shorter cycles, however, do not necessarily imply progress at greater speed, as these innovations are also more incremental than before. Frequent, sometimes even daily, software updates are an example.

4. The digital transformation creates opportunities for innovation in services, as digital technologies allow for reduced costs and greater fluidity in reaching and interacting with consumers and in tracking their behaviour. It also moves manufacturing towards mixed models for providing goods and services.

5. Digital technologies are also relatively young, general purpose technologies (GPTs) that offer new opportunities for innovation. They are both far ranging and fast evolving, hence generating much uncertainty as regards their current and future development. This is particularly true of artificial intelligence (AI), a set of technologies that can emulate functions normally accomplished by human intelligence based on pattern recognition and prediction. Not only is AI expected to transform economic activity, but it also raises complex societal and ethical issues.

Transformations in innovation processes and their outcomes in turn affect business dynamics and market structure, and consequently have implications for the distribution of performance and rewards among businesses, individuals and regions (the influence of digitalisation on these various developments does not preclude the influence of other factors, including globalisation, new financial products, framework conditions etc. Often these various factors interact with digitalisation to either reinforce or inhibit the developments detailed below).

On the one hand, as data are fluid and potentially available to all at a low marginal cost, the cost of market entry and expansion for new firms are lower. Due to this fluidity, different companies and individuals based in different places can exploit the same data, thus opening markets to more participants. This contrasts with traditional markets for tangible goods, where inputs are available in limited quantities and at a significant cost. This has allowed the development of dynamic entrepreneurial activity in a number of markets. The transportation sector, for instance, has seen the emergence of platform-based car-sharing and ride-hailing applications, and in retail there are now start-ups specialised in data analytics that optimise inventories and personalise sales. Similarly, many highly successful start-ups that were created by students using digital technologies and data, illustrating the new dynamics of the intangible economy. Famous examples include Mark Zuckerberg (Facebook), Evan Spiegel (Snapchat), Arash Ferdowsi and Drew Houston (Dropbox) and Nat Turner (Invite Media, an ad tech company that designed a platform for purchasing digital banner ads, acquired by Google). Entrepreneurial activity linked to disruptive business models has also contributed to improvements in consumer welfare. Examples of innovations include digital maps, encyclopaedias and social media. The 
unmeasured contributions to consumer welfare of services for which consumers are not charged have been found to be substantial (Brynjolfsson, Eggers and Gannamaneni, 2018). Digital platforms also facilitate entrepreneurship by lowering set-up costs for newcomers, as for example in the case of e-commerce platforms (e.g. Alibaba, Amazon and eBay) on which new ventures can offer products to the market without having to deal with additional marketing expenditures. Such platforms also gather very accurate information on the activities of the companies that use them - who their customers are, how their sales are evolving, what their marketing costs are, etc. That puts platforms in a favourable position to provide funding to the platform-using companies as the information asymmetry (usually a barrier to the funding of SMEs) is minimal. Amazon is proposing a lending programme for small businesses that sell on its websites (Amazon Lending).

On the other hand, several factors may favour concentration. One is the natural advantage of platforms - Internet-based structures that organise interaction among different actors in increasing market efficiencies. There are important efficiency gains to be had from combining data to optimally exploit the information and knowledge they contain; the natural advantage thus goes to large aggregators of data. Similarly, the provision of combined services on a single platform that brings together a larger group of users offers major consumer benefits. In other words, several small platforms that provide fewer services, have fewer users each, and build on fewer data would be much less efficient than a single, large platform. Such economies of scale are a characteristic of natural monopolies. The second factor arises from "scale without mass", a consequence of the increasingly intangible attributes of products. The larger the intangible component, the easier it is to expand production to the entire market at little or no cost. In the extreme, as in the case of software, the cost of producing an additional unit is close to zero since no further set-up costs are involved. The much smaller number of employees of certain digital companies compared to companies in traditional industries with similar sales levels illustrates this dynamic. A third factor is the scarcity of certain elements required for efficient exploitation of data: skills are the most important of these. Such scarcity may favour concentration, as skilled workers are - up to a certain team size - more efficient when employed jointly (in some firms or places), due to intra-firm knowledge exchanges.

The balance between factors favouring and hampering concentration varies over time and sectors, and can be influenced by policies. Polarised market structures characterised simultaneously by both dynamics are also a possible development, with a few giants on the one hand and a long tail of smaller and fast-changing niche producers on the other. Whereas market concentration is often seen as unfavourable to competition, entrepreneurial dynamics is a strong competitive factor. The coexistence of concentration and entrepreneurship on market raises therefore new questions on competition, and therefore on innovation as competition is recognised as a key enabler of innovation (OECD, 2015a, p. 82).

Similar distribution dynamics apply both to the pre-tax incomes of individuals with diverse skills and to places, with big cities offering best skill mixes. Skewness is reinforced by the fact that markets are now globally integrated, whereas in the past national borders shielded places, people and firms from foreign competition, hence limiting global concentration. Modern innovation policies are designed also in consideration of their impact on society and such features should not be ignored by policy makers (OECD, 2015a, pp. 16-17).

These transformations of innovation require fundamental changes to innovation policies that would affect not only general policy objectives but also specific instruments, as outlined in Table 1. 
Table 1. Policy issues and instruments requiring change to be effective in the digital age

\begin{tabular}{|c|c|c|}
\hline & Policy issue & Policy instruments \\
\hline \multirow{4}{*}{$\begin{array}{l}\text { Innovation } \\
\text { processes \& } \\
\text { outcomes }\end{array}$} & Data is the main source of innovation & $\begin{array}{l}\text { - } \quad \text { Data access policies } \\
\text { - } \quad \text { Markets for data and knowledge }\end{array}$ \\
\hline & $\begin{array}{l}\text { Ecosystems (innovation is more } \\
\text { collective and diversified) }\end{array}$ & $\begin{array}{l}\text { - Support to co-operation while avoiding collusion } \\
\text { - Public research policies, knowledge transfer and co- } \\
\text { creation policies }\end{array}$ \\
\hline & $\begin{array}{l}\text { Acceleration in innovation as digital } \\
\text { technologies, notably Al, are GPTs }\end{array}$ & $\begin{array}{l}\text { - Improving the adaptability, reactivity and versatility of } \\
\text { instruments, policy experiments } \\
\text { - } \quad \text { Revisit public procurement and "picking" technologies } \\
\text { - Instruments to support technology diffusion, incl. to SMEs } \\
\text { - } \quad \text { Policies to support digital technology development }\end{array}$ \\
\hline & Servitisation & $\begin{array}{l}\text { - Support to innovation in services, adjusting instruments, } \\
\text { covering more training, etc. }\end{array}$ \\
\hline \multirow[t]{5}{*}{$\begin{array}{l}\text { Market } \\
\text { structures \& } \\
\text { dynamics }\end{array}$} & Firm entry and entrepreneurship & $\begin{array}{l}\text { - } \\
\text { - } \\
\text { - } \\
\text { - } \\
\text { Comptrepreneurship polion }\end{array}$ \\
\hline & Competition at a global scale & $\begin{array}{l}\text { - } \text { Data access policies } \\
\text { - } \quad \text { Competition } \\
\text { - } \quad \text { National innovation policies in a global market }\end{array}$ \\
\hline & $\begin{array}{l}\text { Distribution of performance and } \\
\text { rewards across skill categories }\end{array}$ & $\begin{array}{l}\text { - } \\
\text { - } \\
\text { - } \\
\text { - } \\
\text { Siscal pocial policies }\end{array}$ \\
\hline & Geographic concentration of innovation & - $\quad$ Cluster and other place-based policies \\
\hline & Skills complementarities and shortages & $\begin{array}{l}\text { Skills and training policies for individuals and firms, } \\
\text { including organisational/management support }\end{array}$ \\
\hline
\end{tabular}

The new landscape for and features of innovation call for changes to the targets, mechanisms and instruments of innovation policies. Some innovation policy domains will adapt their target or content to digital innovation while essentially preserving their processes: that includes for instance policies supporting entrepreneurship, SMEs and generic technologies. Other domains will go through in-depth transformations, sometimes involving their rationale: that includes science policy (moving towards open science) and policies supporting university-industry linkages (moving towards co-creation). There are also a number of cross-cutting themes that apply to all sectors, including the need for engaging with the public to address fears and avoid technology backlash; setting national policies in view of global markets; and equipping government with access to skills and data to manage the process. 
The effective development of digital innovation also requires government to adopt a policy mix, which includes introducing an entirely new policy domain - access to data - to the existing policy domains subject to the transformations outlined above. The mix would comprise the following priorities:

- having a strong public research system (science policy)

- having large, competitive firms and vibrant entrepreneurship (entrepreneurship and competition policies)

- providing sufficient support and incentives to innovation (innovation and intellectual property policies)

- having a skilled labour force (education and training policies)

- ensuring the broadest access to data and knowledge while respecting constraints in relation to data diversity, trust (privacy, ethics, etc.), economics (firm competitiveness and competition, intellectual property rights) and national policy considerations (access to data policies).

The OECD-wide horizontal Going Digital Project presents an integrated policy framework for making the transformation work toward growth and well-being. This framework explicitly considers "innovation" as an area in which multiple policy domains need to be considered, including science and technology, digital government, entrepreneurship and SMEs, competition, and sectoral policies such as energy, finance, education, transport, health and education. It aims to provide a guide to cutting across policy silos to ensure a coherent and cohesive whole-of-government approach, to fully realise the potential of digital transformation and address its challenges.

The remainder of this paper is structured as follows. Section 1 reviews the effects of the digital transformation on the economics of information and knowledge. Section 2 discusses the consequent micro-level changes to innovation processes and outcomes. Section 3 analyses the implications of micro-level changes on market dynamics, market structure and the distribution of income. Section 4 draws implications for innovation policy. Section 5 concludes. 


\section{Impacts of the digital transformation on handling information and knowledge}

This section discusses the two major mechanisms through which digital technologies affect the handling of information and knowledge: the price system (with reductions in related costs); and the allocation system of information and knowledge (with increased fluidity). A comprehensive account of the properties of the digital transformation and its implications for policy is provided in (OECD, forthcoming). The changes described in this section are ultimately a consequence of the distinct features of the production of intangibles, as opposed to tangibles (Haskel and Westlake, 2017).

\subsection{The price system}

Digital technologies reduce several types of costs: 1) the marginal costs of producing intangible-intensive goods and services (due to the non-rivalrous nature of information and knowledge) and 2) the costs of searching, verifying, manipulating and communicating information and knowledge. These cost reductions lead to a substitution of tangible for intangible products.

\section{Marginal costs of production of products with information and knowledge content}

In the case of entirely digital products, the production of another copy of an original (i.e. the marginal cost of production) is simply replicating bits, which is practically costless. The savings arise from the non-rivalrous nature of information and knowledge, which makes them ubiquitous and reusable without further cost and without wearing out. These features apply more to digital innovations than to past innovations where the physical product component represented an important share in products' value. While only fully intangible products see their costs fall to zero, most products see their marginal cost decrease to the extent that they are partly digital. The term used here to clearly indicate the changing landscape (and its different implications) is digital non-rivalry (DNR). DNR additionally means that bundling comes at little cost and can be optimal by increasing information content at little additional cost.

Marginal cost reductions apply to both goods and services. While most manufactured goods produced in the digital economy are by nature tangible, the proportion of the product that is intangible is much higher than in the past. Cars are a good example: the software component figures increasingly in development costs and in the characteristics of the product. A similar evolution arises across all manufacturing products with the Internet of Things (IoT). Services have always been "intangible" as they are by nature immaterial, but marginal costs were often significant because of a significant human component. Technological advances (e.g. in automated translation) are reducing those costs and facilitate scaling. The major change in services that has led to reduced marginal costs of production is the development of new avenues for reaching customers - notably online platforms - that facilitate and lower the costs of serving additional customers. Ongoing work of the OECD-wide Going Digital project analyses in depth the economic and social impacts of online platforms. 


\section{Search, verification, communication and product launch costs}

First, with the Internet, search costs have declined: it has become less costly for customers to locate products corresponding to their taste, and for producers to find potential customers. Customers benefit from the precise descriptions offered by specific online platforms. Sellers meanwhile benefit from platforms that gather personal data from customers' online activities. Profiling of their preferences, building on sophisticated algorithms, has resulted in truly personalised product offers and personalised pricing. For instance, Google analyses search queries entered into its search engine and clicks on web pages to measure users' behaviour. Based on this performance data, the company presents each user with individual advertising messages. Then, based on users' reactions, Google measures in real time the effectiveness of its banner ads, optimises their allocation model, and uses the same data to invoice its advertising customers.

Extending beyond customer-producer matching, the reduction in search costs also applies to opportunities for producers to identify suitable partners (whether other firms or universities) for joint research, innovation and production. It also facilitates new forms of open innovation - as exemplified by InnoCentive, a platform on which companies can pose innovation challenges to anyone on the Internet - and new forms of finding funders for projects, for example by presenting projects on dedicated websites. Several services - both public and private - have also been developed to offer companies information on research institutions and researchers working in closely related fields, by combining large data from publications, patents and other available information on research grants, etc. For example, Australia's Data61, a public R\&D centre devoted to data-driven innovation, has created Expert Connect, a searchable database that contains profiles of over 45000 experts and combines them with other datasets such as global patent data (Data61, forthcoming).

Second, lower costs in verifying the reputation and trustworthiness of possible partners with digital technology further increase opportunities for successful matches (Goldfarb and Tucker, 2017). Track records of past performance and testimonials of past experience from others (e.g. online reviews from users of Uber and Airbnb) can help reduce information asymmetry gaps and make transactions possible. Blockchain, an authentication technology, in particular may offer important opportunities for low-cost verification (Catalini and Gans, 2016).

Third, lower costs of moving information allow for cheaper communication. It can be a bilateral exchange of information, or direct interaction among large numbers of actors, one to many or many to many. Furthermore, communication leaves a track record that can be stored and shared, so that communication outcomes can be capitalised on and disseminated. Traditional multilateral communication is most often transient and has little memory. By contrast, when it is digitalised, multilateral communication becomes a network, with wellidentified and more stable actors and links. This facilitates all sorts of transactions among participants (gains from trade), which generates network externality (as more participants mean higher value for each one).

Fourth, in the case of new products, digital tools allow customers to be reached much more easily (e.g. through optimised distribution networks, the use of marketplace platforms, and digital advertising). The pace of diffusion of digital products through the Internet is also much faster: it takes a few seconds for a digital product to be accessible around the globe, without the need to change and upgrade factories, build up inventories, or possess a physical distribution channel. 


\section{Towards a substitution of tangible products with intangible products}

The reduction in costs encourages a substitution of tangible/physical goods, components or processes with intangible products wherever this is feasible. Many functions that used to be performed by physical devices are now performed by software. This means also that changes in the functioning of industry apply far beyond purely digital industries, as virtually all products are not only partially digital but also partly produced digitally. One example is Lego, a construction toy consisting of interlocking plastic building blocks. While plastic Lego blocks still exist, there are now digital Legos that can be manipulated on a computer. Newspapers also still exist but have been substituted by new Internet services. Many complex physical products, e.g. engines, even entire factories, now also have a digital twin that can be studied and manipulated to test breakdowns, etc.

\subsection{New mechanisms for allocating resources}

\section{Rapidity, instantaneity, fluidity}

Digital non-rivalry (DNR) not only means reduced marginal costs, but also means rapidity, instantaneity and fluidity ("frictionlessness"). In high-frequency trading, there is almost no delay between the moment a decision is taken and the moment an action is implemented and even effective, at any distance. The same type of dynamics applies in the digital economy to the commercialisation of new products and the diffusion of knowledge. This fluidity ("scale without mass") allows for scaling up to serve entire markets much more rapidly (favouring both new entry and "winner-take-all" market dynamics, as described below). This contrasts with tangible goods, which are subject to physical constraints in production and distribution.

\section{Equal access but unequal outcomes}

As information and knowledge become digitalised, DNR ensures potential access to information and knowledge to all, hence a sort of equality of opportunities. Many scientific or public sector databases, for instance, can be accessed by anyone, but so can certain valuable private sector data (e.g. scientific publications subject to copyright). For example, the US National Institutes of Health (NIH) has a database (ClinicalTrials.gov) that provides researchers with access to information on privately and publicly funded clinical studies around the world, including study protocols, purpose, and results. The database of Genotypes and Phenotypes ( $\mathrm{dbGaP})$ also provides access to data and results from studies that have investigated the interaction of genotype and phenotype in humans (Sheehan, 2018). This contrasts with physical goods, for which equal access is essentially restricted to public infrastructures, the rest being subject to payment-based selection. Hence digitalisation potentially creates a more level playing field for all in terms of access to several inputs (provided that no regulatory or strategic barriers are in place).

However, equal opportunity in accessing data can translate into unequal achievement. Creating value out of data requires complementary assets, individual skills, collective and organisational competencies (i.e. the right institutional setting to exploit information) and data assessment tools. What is new is that the better achievers can potentially access all data (notwithstanding obstacles to data access, which can be substantial, but are due to market actors, not to physical costs), drawing on their advantage more than was the case before, when the lowest achievers could still secure exclusive access to certain assets. With data, all physical barriers have been removed. Anyone can potentially access all data and draw on their efficiency advantage, however small it is over others (as the whole market becomes integrated). At the individual level, this allows top entrepreneurs to command 
larger production teams and take decisions with key data (Garicano and Rossi-Hansberg, 2006). At the organisational level, it allows firms with the strongest capacities to fuller take advantage of those data. Finally, at the geographical level, top cities or regions in the world have the potential to access data and build prosperity on their exploitation (Kerr and Kominers, 2015). 


\section{Impact of the digital transformation on innovation processes and outcomes}

This section investigates how the reduced costs of knowledge/information and increased fluidity brought on by the digital transformation affect the way innovation is conducted and its outcomes.

\subsection{Data as a core input for innovation}

\section{New ways that data feed into innovation}

The reduced cost of gathering and analysing information/knowledge has boosted the supply and demand for data of various types (see below), making them available in large quantities and pervasive across the economy and society (OECD, 2015a). This transformation is evident in connection with many products, such as the on-demand urban transportation systems offered by Uber, Lyft and others. In fact, information on the current supply and demand of transportation is the very basis of the service those systems offer. Less evident but equally important are data generated in production processes, public sector data (dealing with transportation, patient files, etc.) and research data (such as data from experiments).

Innovation processes themselves also rely increasingly on data; some of them are even extremely data consuming. AI-based innovations come from the implementation of an algorithm, which often learns from real world or simulated data. Machine learning-based innovations require large numbers of observations before the software is able to perform the expected task, although there is currently much research in AI aimed at reducing the amount of data needed to train a programme. The development of IoT also means that data generation is increasing steadily as more devices and activities are connected consequently, the overall value of data is also ever increasing.

\section{Data types}

Main categories of data relating to innovation are a) personal data, b) business and innovation data and c) government and research data. First, personal data include the following types:

- Personal data on social media and search websites, including personal profiles and track records of individuals' exchanges and navigation on the web. Such data are valuable for analysing consumer preferences and product demand. They are directly relevant for advertising purposes, as illustrated by the Google example presented previously. The recent European General Data Protection Regulation (GDPR) will, however, give European users of the Internet more control over the use of their data.

- Customer and transaction data (airlines, banks, retailers etc.). These data are provided by customers when navigating private, closed and usually confidential spaces. They are of great value to the company concerned, as they allow it to learn about demand for its products, customer behaviour, etc.

- Patient data are generated by hospitals, clinical research, health care processes and various types of testing (including DNA). Essential to health innovation, they raise particularly important privacy concerns. The OECD Council on Health Data 
Governance agreed on a Recommendation that lays out the framework conditions to encourage greater availability and processing of health data within countries and across borders for health-related public policy objectives, while ensuring that risks to privacy and security are minimised and appropriately managed. Other areas where citizens interact with public or semi-public services (education, taxes, local government etc.) raise similar issues.

Second, business and innovation data are produced by companies as part of their innovative process (research, testing, etc.) and business processes (marketing, financing, logistics, maintenance, remote control, etc.). They can be either purely internal (e.g. data on "digital twins" of a company's product) or partly external (data on monitoring a company's equipment installed in another company's facility). Such data are important for developing innovations and providing new services (e.g. higher customisation, predictive maintenance). All sectors, notably the very traditional ones, are very much affected and could benefit from efficiency gains. One notable example is precision farming, which uses geographical information systems (GIS) data, soil information, and details on weather and environmental conditions at the field level to optimise the management of the production process: choice of crop, when and how to apply inputs to the crop (e.g. pesticides, fertilisers, water management) and when to till or harvest specific crops.

Third, government and public research data are generated by various government activities and services (meteorological service, transportation authorities, space agencies, etc.) but also by public research and academic activities. These data hold great potential for innovative products with important welfare contributions, as illustrated by the uses of traffic data to improve circulation in urban areas. This categories includes some patients data and other Government collected personal data (tax data, social services, etc.) as mentioned above.

\section{Implications for business behaviour}

As a result of this growing importance, the value of data has increased. Many businesses are led to make large investments in order to access and analyse data, be it by setting up data-gathering systems, by acquiring data-rich companies (Microsoft acquired LinkedIn notably in view of accessing its data) or by contracting with partners (DeepMind with London hospitals).

The value that data provide also means that companies will protect their own data from real or potential competitors. While such protection helps address important privacy and security concerns, the downsides may include difficulties for start-ups to enter markets (as they cannot access data) and for data pooling, which may limit data analytics services. Data sharing occurs, but only with non-competitors, and raises privacy concerns as exemplified in some well publicised cases.

There is currently an emerging market for data, facilitated by various sorts of intermediaries, but it is still in its infancy. Trading data is quite complex, particularly in terms of setting the rights that are transferred and the contractual obligations (guaranteeing the integrity of the data, for instance).

\subsection{More versioning and experimentation}

The digital transformation allows for shorter innovation cycles due to the reduced costs of launching new goods and services discussed above. The increase in speed is most obvious from the frequent updates and new versions of software users receive, which contrasts with 
product cycles of several years that characterise many tangible products, such as new car models. The changes are widespread, extending beyond purely digital sectors to (for example) Tesla, which regularly provides updated versions of its software, thus introducing a much quicker product cycle than in the past. Updates are embedded in the new car while the hardware component is unchanged.

Experimenting directly with products already on the market has also increased for similar reasons. In the past, as launching products involved substantial costs (in producing and marketing them), a recall made necessary in the case of a defective product would be costly, and thus the product needed to be as perfect as possible at the first launch. Today, testing can be done directly with customers at a low cost. For example, Ezoic is an ad-testing platform that uses AI and machine learning to test ad combinations to optimise the position, size and colours of ads (Ezoic, 2018). Full scale ("beta version") testing is also often done by Google and Facebook. One factor that may, however, hold back immediate testing with customers is any impact on brand reputation that may come from launching an incremental innovation that is defective or simply judged to be of less value by customers.

Aside from the reduced costs of launching and diffusing products, another push factor of the digital transformation is the cumulative nature of upgrades, which reduces the cannibalisation of products (i.e. the creative destruction of its own product by a company): when a firm issues an innovation, it might simply add to products already on the market and be downloaded as an "add-on". Hence, as opposed to, say, a new car model, the new digital product will not replace existing products of firms, but instead reinforce them.

Moreover, if "superstar" effects are in place, a small advantage over competitors might allow seizing all of the market, hence increasing the expected reward in case of successful, even minor, advance (but also increasing the risk). Consequently, firms have an interest in updating and launching new versions to gain or maintain lead positions.

Acceleration in versioning and innovation is not synonymous with more rapid technological progress and productivity; many of these frequent improvements are small. Technical change may have become more continuous, but it is not necessarily faster. The cost of developing innovations is not necessarily affected by the digital transformation to the same extent as that of their commercialisation. There is an ongoing debate about decreasing returns to investments in research in the past decades (Bloom et al., 2017), and AI might help restoring higher returns (Cockburn, Henderson and Stern, 2018). The new dynamics of commercialising more rapidly to directly test with consumers may boost innovation if consumer feedback is integrated in adequate ways into innovation processes.

\subsection{More collaborative and diversified innovation}

Reduced costs of communication allow densified interactions among companies, possibly involving public research, that to some extent ignore distance. Entirely new forms of open innovation are feasible, not only with dedicated interactions but also through more active collaboration with communities of experts and consumers. External sourcing practices (procurement) - involving tournaments, collaborations, open calls and crowdsourcing - are new ways for firms to address innovation challenges. Some of these practices will create a team for repeated interactions, while others will be one-off only. Examples of corporate initiatives include BMW Innovation Lab, the Peugeot design contest, IBM's InnovationJam, Dell's IdeaStorm, Proctor \& Gamble's Connect + Develop and GE's Fuse (Board of Innovation, 2018). In other cases these practices are conducted through intermediary platforms, such as InnoCentive, IdeaConnection, Innoget, Hypios CI 
(CrowdInnovation) and NineSigma. Successfully harnessing the potential of digital technologies requires combining different technologies used for specific purposes into systems that deliver complex goals such as "actionable insights" relevant to a specific challenge. Actors may also engage in more collective innovation processes in order to hedge against risk from disruptive innovations introduced by competitors, a risk that will be perceived to be much higher in a context of general purpose technologies (GPTs).

This enhanced interaction can take different forms, including data sharing, open innovation, innovation ecosystems, acquisitions, and global value chains (GVCs):

- Data sharing is becoming easier, and the non-rivalrous nature of data and digital knowledge allows the same database to be used simultaneously by various actors from different organisations, even located around the world. At the same time, the strategic role of data also affects what will be shared, driving attempts to limit access where those data constitute strategic advantages. Data localisation measures can restrict cross-border data flows.

- Open innovation refers to innovation beyond the boundaries of the firm. It involves collaborations with other business, public research and university partners. This cooperation can be about collaborating in research, dividing research work between partners, pooling results, etc. Open innovation existed before digitalisation, but has progressed with it because of cost reductions as well as other push factors (such as the advantages from interdisciplinary work, notably involving computer sciences and the blurring of industry definitions).

- Innovation ecosystems are made up of groups of businesses (small and large, old and new) engaged together directly or indirectly in open innovation, plus universities, capital (notably venture capital, VC) and service providers (e.g. intellectual property [IP] management). Boosted by new opportunities from price and allocation mechanisms, these ecosystems constitute the locus of most innovation. They have also taken on new forms. In the field of AI, there is an open standards approach taken by companies like Microsoft, Facebook and Google; they open platforms where innovators can come and borrow tools and upload their creation. Hence they constitute a community of developers. Opportunities to expand ecosystems have also increased with new opportunities to solicit contributions to innovations or crowdfunding sites (such as InnoCentive), increasing the possible range of contributors to innovation ecosystems beyond geographic boundaries.

- The acquisition of innovative firms (particularly start-ups) by established firms is also a channel for collective innovation. In this model, start-ups play a role of pilot fishes: they prospect new avenues, markets or business models, and when it works they are usually acquired by larger firms with access to capital and markets that can scale up the successful product. This has been systematised by many large companies that have set up their own VC fund, which allocates capital notably but not exclusively to spin-offs created by in-house engineers with breakthrough ideas.

- Global Value Chains (GVCs) connect suppliers with integrators across the globe and allows for collective innovation by producers in production chains using digital tools. Where compatibility of components is essential, this type of co-ordinated innovation is essential. Typical examples include mobile phones and the automobile industry. 


\subsection{The blurring frontier between manufacturing and service innovation}

The digital transformation of products offers opportunities especially for innovation in services, as data and software are replacing many physical components and products. Opportunities arise in particular from digital possibilities for i) entirely new services, such as predictive maintenance services using IoT, Uber's on-demand transportation services, and the provision of web-based business services; ii) renting (as a service) or sharing instead of selling (equipment); and iii) the customisation of products as a service (i.e. the adaptation to each customer's specific needs, allowed by software and data).

Servitisation is disruptive to business practices, requiring entirely new business models and, what is more, organisation of the economic activity away from manufacturing. The strategy and innovation activity of a large number of manufacturing firms now follows the "3 S's": sensors, software, and service. For instance, Siemens, a producer of a wide range of consumer and industrial appliances, installs sensors on many of its appliances that are monitored by software, allowing for more effective maintenance services for customers.

Conversely, service firms are also entering manufacturing (autonomous cars, home appliances, mobile phones, computer chips, data centres, etc.), blurring further the frontier between manufacturing and service. Amazon is an illustration of this move into manufacturing. The company has its own private label brands (Thomson, 2018) and owns a patent for an on-demand clothing manufacturing warehouse that enables the firm to quickly produce tailored clothing only after a customer order is placed (CB Insights, 2017).

These dynamics also affect competition. The trust guarantees provided by Amazon as a multi-product provider may, for instance, result in an erosion of the value of traditional product brands that previously were trust guarantees. Specific domain knowledge by contrast strengthens the value proposition of traditional producers in providing their own enhanced services. Offering such services across different domains is more challenging for multi-product providers as there are fewer economies of scope.

\subsection{Digital technologies and artificial intelligence as general purpose technologies (GPT)}

Digital technologies, including AI, are general purpose technologies that affect all economic and social activities, including research and innovation. AI will transform research agendas and enable the development of new research fields.

Such a fundamental change increases uncertainty, with regard to both technology (what will be feasible with the technology as it is more developed, and when) and demand (what consumers will require). As is the case for technology adoption generally, uncertainty delays adoption, particularly among smaller players, as the stakes are much higher. Substantial investments that fail to deliver will put the very survival of the firm at risk. Due to the network dimension of a number of digital technologies, a firm's decision to adopt a particular technology is also a bet on what technology people are likely to adopt, generating herding behaviour and favouring collective choices that may not be optimal from a technical perspective ("technology lock-in"). 


\section{Economy-wide effects of digital innovation: Business dynamics, market structures and distributional effects}

\subsection{Drivers of new business dynamics and market structures}

\section{Platforms and interoperability for efficiency}

The fluidity of data allows their circulation in all sorts of channels and networks. One such network is platforms, here defined as Internet-based structures that organise interaction among various sorts of actors. Platforms play an important role in digital innovation: they facilitate access to knowledge (patent and publication databases) and research infrastructures, and allow producers and consumers to meet more easily (including for niche products). They thus enable fluidity, in that they reduce frictions and barriers that previously affected matching of supply and demand. Interoperability between the involved parties is a key service platforms provide to the economy, offering substantial efficiency gains that would otherwise not be possible. Ongoing work of the OECD-wide Going Digital project analyses in depth online platforms.

This central role of platforms in the digital economy can be a basis for their acquiring of strong market positions. However, there is ongoing debate regarding the contestability of market positions of platforms. A dominant platform today may be replaced by another platform tomorrow, particularly if shifting across platforms comes at low cost for customers (aspects such as multihoming i.e. the ease at which consumers can switch from one to another and use multiple platforms come into play here). Moreover, new technical opportunities may challenge the current position of platforms. In particular, according to some observers, blockchain could allow for fully decentralised systems that process information on the market for and characteristics of demand/supply - offering, for instance, car-sharing services - and could so suppress the need for intermediaries (Catalini and Gans, 2016).

\section{Scale without mass}

Digital innovations allow for scaling products up to the full (sometimes global) market without incurring the major costs that would be necessarily for tangible products. The production of a car requires setting up production facilities to produce more goods, while additional software units do not require much additional production inputs. The radical reduction in the marginal costs of production, exemplified by software for which marginal costs are close to zero, extends to all products with important intangible components. The process generates a disconnect between firm size in terms of staff on the one hand and sales or reach on the other ("scale without mass"). WhatsApp was sold in 2014 to Facebook for USD 22 billion with a staff of 70; the turnover per employee of companies like Google or Facebook is many times higher than the turnover per employee of manufacturing companies. The scale without mass phenomenon is driven by DNR, which drastically reduces the cost and time of replicating any digitalised product - hence of dramatically expanding the production level. 


\subsection{Effects of platforms and scale without mass on markets}

The dynamics of innovation is both a determinant and an effect of market structures (OECD, 2015b). Hence, understanding the development of digital innovation and its impact requires to analyse their connection with market structures, which can be done from various angles. The dynamics of platforms and scale without mass may be contributing towards a polarisation of market structures. On the one hand there are drivers of the entry and growth of new and small companies, and on the other factors that may promote market concentration. It is an environment in which middle-sized companies may find themselves in fragile positions. As stated in the OECD Secretary-General's Ministerial Report of 2017: "The digital economy has brought new business models and rapidly expanding industries. Indeed, never before have leading firms grown so large so quickly, and new businesses are challenging incumbents in novel ways" (OECD, 2017a). Competition in the digital economy could be affected by many factors, including network externalities (i.e. the benefit from the network rises with the square of the number of users), which are particularly prevalent in certain markets. These externalities can lead to growing concentration and winner-take-most dynamics in such markets (Autor et al., 2017). In principle, this raises no competition problems if any resulting market power is temporary, not due to anticompetitive behaviour, and/or the resulting rents are eroded by competition, including from other firms and new business models [OECD (2013), (2016a), (2017b)].

The factors driving the entry and growth of new and small companies - and consequently, increased competition as these firms challenge incumbents - include the following:

- Data, a key input for innovation, are potentially (in the absence of legal or economically built barriers) accessible to all without a technical limit, thanks to DNR: most barriers are legal or strategic. Hence, potentially, a small company has access to the same pool of data (e.g. from public open data portals) as a large one, although it might choose to use less of them at the end.

- Software production is less capital-intensive than manufacturing. Consequently, creating a digital company requires much less capital than creating a manufacturing company, because the equipment and inventories required to process physical goods are not needed.

- The cloud and off-the-shelf digital tools - including open source software, open access depositories of data, and information and knowledge available on line reduce costs for small firms and new entrepreneurs. The largest cloud service providers (i.e. AWS, Google Cloud, Microsoft Azure, etc.) increase the offering of services while pursuing competitive pricing strategies (Weins, 2017).

- Direct access to global markets thanks to reduced communication and product dissemination costs (with the Internet and, in particular, via platforms) facilitates market launches. In principle - depending on platform dynamics - this allows smaller firms to benefit from reduced set-up costs. Firms can now directly sell their products via online marketplaces such as Amazon, eBay and Etsy; or they can create their own online store, building on the tools and advice offered by e-commerce software providers such as Magento and Shopify.

- Consumers with rare tastes (specialised niches) can be served by specialised firms, selling to customers with specific, differentiated preferences. A customer from New Zealand can discover and connect with a potter from Sweden, which was difficult to imagine before. Such niche firms used to be restrained by their limited ability to 
reach customers. Using data from a retailer with both online and offline channels, Brynjolfsson, Hu and Smith (2010) show that the variety of products available and purchased online is higher than offline.

- Platforms offer access to customers/suppliers as well as readily developed rules of contracting, consequently reducing set-up costs for smaller and new players (see, for instance, Brynjolfsson, Hui and Liu, 2018).

At the same time, market concentration is driven by a number of supply- and demand-side forces. On the supply side, massive scale economies and increased fluidity mean that barriers to the expansion of successful ventures no longer exist, pushing toward "global stars" with little room for "local stars". This stands in contrast to the tangible economy, in which barriers of different types - notably costs of transporting products, of differentiating them etc. - act as barriers that allow firms that are not among the best globally to keep serving certain protected (often national and regional) markets. Such concentration may, however, enhance productivity if it results in eliminating less efficient firms and if dominance is constantly challenged by new providers of improved services. On the demand side, network externalities may generate superstar effects that consolidate the position of large players across many sectors of the economy. Those effects are facilitated by the efficiency advantage due to aggregation (pooled data and services). The dynamics of the "attention economy" - where consumer time is the unexpandable, scarce resource that service providers are competing for - pushes towards concentration and away from diversification of suppliers, as each customer will allocate her consumption (time) to a restricted number of preferred products. This is reinforced in certain cases by scale economies in use: To use services, consumers must spend time understanding how they operate, bringing an advantage to incumbents.

The balance between these two contrary forces depends on various factors that can differ across industries and over time. With regards to industry differences, the balance depends on the respective strengths of horizontal versus vertical differentiation of products. When vertical differentiation dominates markets (i.e. products differ only in quality), market concentration will be higher since reduced search costs with digital technologies offer opportunities to scale. As for horizontal differentiation (as a result of consumers' differences in tastes), a large number of smaller firms might provide different products, depending on the extent to which economies of scope operate (if those economies are sizeable, then a few large companies might serve the entire market as they can differentiate their offer efficiently). (See Bar-Isaac, Caruana and Cuñat, 2012 for a discussion of superstar and long-tail effects.)

An open debate is under way on whether some markets have reached maturity to the extent that the position of key players is no longer contestable. However, what may look to be a fairly consolidated market today could be challenged tomorrow with new technical avenues pioneered by a start-up, as has happened in the past. This outcome contrasts with dynamics whereby start-ups with good ideas are simply acquired by large incumbents. Examples include Volkswagen's recent acquisition of the Canadian mobile payments start-up PayByPhone, and SAP's acquisition of Recast.AI, a French start-up that focuses on natural language processing technologies.

Outcomes will also depend on policy, which in turn needs to determine whether market concentration is or is not a problem. The answer to this question may be specific to particular markets and mainly depend on whether the degree of market concentration is a hindrance to innovation. Platforms have an efficiency-enhancing effect in that they create standards that facilitate innovation and allow network dynamics, data aggregation, and all 
the resulting benefits. At the same time, possible reductions in competition and lock-in to inefficient standards need to be avoided.

\subsection{Distribution of performance and rewards: People and places}

The same mechanisms that affect market dynamics in the digital economy also have implications for the distribution of performance and rewards across places and people. The fluidity of digitalised data makes them potentially accessible in all places and to all individuals, hence facilitating widespread access to this core input to innovation. Data complement collaborative and individual competencies and skills, which are not evenly distributed. Data will consequently increase productivity most for those individuals, companies and places that have the right set of competencies to exploit data, possibly resulting in concentration of performance and rewards. The concentration of outstanding innovation performance in specific places, firms and individuals is not new to the digital economy. However, the increased availability of the core input to digital innovations - data $\&$ data analytics tools - together with the possibility afforded to launch innovations on the global market, increases the productivity and returns to the best performers.

The reduction in costs, in particular of communication, and the fluidity of data also imply an easing of geographic boundaries. These forces might make innovation more widespread geographically than in the past.

However, innovation hotspots retain their importance, and large cities have seen their importance in the digital economy increase. The concentration of highly innovative companies in Kendall Square close to MIT in Cambridge, Massachusetts demonstrates the role of extreme proximity, notably for research activities. Skilled workers benefit from close interaction, and skilled labour is complementary to data. Interpersonal contact is still important to knowledge sharing. With a more diversified set of expertise needed for digital innovations - as exemplified by the modern car that requires optimised engineering and computing skills - skills needed to best exploit data opportunities can best be found in urban areas that pool large numbers of persons possessing different kinds of expertise. The rise of cities also reflects the complementarity of non-codified knowledge with codified digital knowledge. Gaspar and Glaeser (1998) suggest that reductions in communications costs may benefit most those who already communicate a great deal, in which case falling costs would benefit cities most (strengthening concentration further) - this is the current global trend. 


\section{Innovation policy changes required in the digital age}

\subsection{Overview of required changes}

The new context and features of innovation call for changes to the targets, mechanisms and instruments of innovation policies, and to the policy mix for innovation. This is because, as discussed in the previous sections, digitalisation is affecting essentially all mechanisms that drive innovation - exactly those mechanisms that innovation policies are targeting.

The changes called for could affect the entire innovation policy spectrum (see Table 1 above), to varying degrees across policy domains. The degree of transformation depends on the extent to which the field in which the policies operate is affected by digitalisation, as outlined in Table 2. Some domains will adapt their target or content to digital innovation while essentially preserving their processes; this includes for instance policies supporting entrepreneurship, SMEs and generic technologies. Other domains will go through in-depth transformation, sometimes including that of their rationale: that includes science policy (moving towards open science) and policies supporting university-industry linkages (moving towards co-creation). There is debate about the changing competition policy [see OECD (2016a), (2017b), (2018)], which is critical to innovation as only the right competitive environment will spur firms to innovate and ensure innovation-driven growth (Romer, 1990; Aghion and Howitt, 1992). Access to data has become a major new theme in all policy domains relating to innovation, such as innovation support, public research and competition. It has also become a policy domain itself, and subject to issues such as confidentiality and privacy, etc., that directly impact innovation.

There are also a number of cross-cutting themes that apply to all sectors, including the need for greater responsiveness and agility of policies; engaging with the public; setting national policies in view of global markets; and equipping government with access to skills and data to manage the process.

Effective development of digital innovation also requires that government adopt a policy mix that reflects the transformations outlined above. The mix should comprise the following priorities:

- having a strong public research system (science policy)

- having large, competitive firms and vibrant entrepreneurship (entrepreneurship and competition policies)

- providing sufficient support and incentives to innovation (innovation policies, intellectual property)

- having a skilled labour force (education and training policies)

- having abundant and accessible data (data access policies).

Innovation is also influenced by many policies that do not target it explicitly or primarily, such as education, tax, health, environment and transportation policies. As these policies evolve, they will have important impacts on innovation. The focus here is on policies that directly affect innovation. The wider policy questions are addressed by the OECD-wide horizontal Going Digital Project which has developed an integrated policy framework for making the transformation work for growth and well-being (www.oecd.org/going-digital). 
Table 2. Major changes to the main domains of innovation policies called for by digitalisation

\begin{tabular}{|c|c|}
\hline Policy domain & Change required \\
\hline All domains (Section 4.7) & $\begin{array}{l}\text { - Use digital tools to mobilise more information, more actors, etc. in the } \\
\text { design, implementation and monitoring of policies } \\
\text { - Engage effectively with the public } \\
\text { - } \quad \text { Frame national policies in view of the global market }\end{array}$ \\
\hline $\begin{array}{l}\text { Access to data } \\
\text { (Section 4.2) }\end{array}$ & $\begin{array}{l}\text { - Ensure access to data for innovators, taking into account diversity of } \\
\text { data } \\
\text { - Develop appropriate data access schemes, differentiating by types of } \\
\text { data } \\
\text { - Explore the development of markets for data }\end{array}$ \\
\hline $\begin{array}{l}\text { Support to innovation and } \\
\text { entrepreneurship } \\
\text { (Section 4.3) }\end{array}$ & $\begin{array}{l}\text { - } \quad \text { Ensure that policies are responsive and agile } \\
\text { - } \quad \text { Support more service innovations } \\
\text { - } \quad \text { Adapt the IP system } \\
\text { - } \quad \text { Facilitate access to data while preserving rights and incentives } \\
\text { - } \quad \text { Support the development of multi-purpose digital technologies }\end{array}$ \\
\hline $\begin{array}{l}\text { Public research } \\
\text { (Section 4.5) }\end{array}$ & $\begin{array}{l}\text { - } \quad \text { Promote open science (access to data, publications) } \\
\text { - } \quad \text { Support interdisciplinarity } \\
\text { - } \quad \text { Develop co-creation with industry } \\
\text { - } \quad \text { Support training in digital skills for science } \\
\text { - } \quad \text { Invest in digital infrastructure for science }\end{array}$ \\
\hline $\begin{array}{l}\text { Competition \& } \\
\text { collaboration (Section 4.4) }\end{array}$ & $\begin{array}{l}\text { - Review the conceptual framework of competition policies as needed } \\
\text { from the perspective of innovation in the age of platforms \& easier } \\
\text { entry (e.g. new rules regarding takeovers, standards, etc.) } \\
\text { - } \quad \text { Adapt the intellectual property system (protection of data, Al } \\
\text { challenges) } \\
\text { - } \quad \text { Support the transition of SMEs and opportunities for diverse regions } \\
\text { - }\end{array}$ \\
\hline $\begin{array}{l}\text { Education and training } \\
\text { policies (Section } 4.6 \text { ) }\end{array}$ & $\begin{array}{l}\text { Have innovation agencies support improvement of assessments of } \\
\text { skills required for the digital transformation, ensuring youth and } \\
\text { students are properly equipped with these as well as skills for lifelong } \\
\text { learning } \\
\text { - Support proper management and organisational structures in firms for } \\
\text { digital innovation } \\
\text { - Support wider involvement in innovation by disadvantaged groups, } \\
\text { through engagement \& training }\end{array}$ \\
\hline
\end{tabular}




\subsection{Develop data access for innovators}

Due to their fluidity, data have many properties of a public good (DNR); hence they are subject to market failures, and in view of the importance of data as inputs to innovation it makes sense to develop a specific policy agenda (OECD, 2015a). Data access is complex and requires taking into account the diversity of data. General considerations are as follows.

First, the objective is to ensure the broadest possible access to data and knowledge (incentivising sharing, favouring reuse, favouring competition) while respecting constraints arising from data's diversity (access issues differ among the categories of data discussed above), trust (privacy, ethics, etc.), economics (incentives to produce the data, competition, intellectual property), and different national policies regarding data protection. Open access should remain central to the policy agenda, as it facilitates competition (alternative uses of the same data), reuse (hence a gain in efficiency) and transparency (the ability to check the validity of results obtained on a given data set). This is notably the case with data generated by public research or by public services (weather monitoring, urban transportation, etc.). There is also much value in making data accessible not only for future research but also to reproduce and test the validity of scientific research, and to reuse it for conducting further research (OECD, 2015c). Many governments have established open access as a reference, with to promote use of this data by innovative startups. For instance, the United Kingdom's open data portal (data.gov.uk) publishes data from the central government, local authorities and other public bodies on a variety of fields from education, to the environment, health and transport - in order to create new opportunities for organisations to build innovative digital goods and services. The online platform TransportAPI, which provides real-time country-wide information on departures and timetables, as well as journey planning services covering all modes of transportation, was created using such data (TransportAPI, 2018).

Second, regarding private sector data, different criteria to data access may be considered. Data that are core to firms' business could be (and in some countries are) treated as trade secrets. In the case of data generated by the core activity of a firm (e.g. data on the manufacturing and use of its products), opening access might hand critical information to competitors, which would be to the detriment of the firm itself. It may also allow competitors with higher data-processing skills to establish themselves as intermediaries between themselves and their customers, which may not always be conducive to innovation in these sectors. SMEs in particular may be challenged by large firms' uses of big data. The example of the press and newspapers illustrates this point. Internet platforms, which have become the intermediaries needed between newspapers and readers, are now seizing a significant share of the advertising income that formerly went directly to the press. Content producers have therefore seen their income reduced to the point that it risks limiting their production. Revenue sharing arrangements are being negotiated with Internet platforms with a view to ensuring the sustainability of those actors. Such arrangements are very sensitive to the legal copyright context.

Third, government should also set up appropriate conditions for the emergence of markets for data. The development of knowledge markets, which were previously focused on IP rights, has been viewed positively by economists (Yanagisawa and Guellec, 2009). Trading data may not only facilitate the exchange of data for innovation purposes, but also allow putting a price tag on data generation and curation for future use - thus facilitating the generation of more data. Such markets also promise entry to start-ups that do not hold such data but that require them to develop their business. Data marketplaces could allow trading raw data on digital platforms as well as normalised and standardised data to 
facilitate their immediate application. Moreover, there are opportunities for data aggregators and quality assurers that provide access to bundles of data that have been verified and validated (Deichmann et al., 2016).

There are major challenges to the development of knowledge markets. Issues relate notably to the specificity of data (data are often adapted to a specific context, out of which they may have little or no value), which limits their transferability. Informational and appropriability difficulties, as well as difficulties in evaluating the true market value of data and the quality of such data, pose further challenges. There are also privacy and safety aspects affecting personal data - anonymising data is increasingly impossible - and justified questions about their tradeability by data aggregators.

Some of the obstacles to the development of data markets may be mitigated with new digital tools: a) the Internet (platforms) and AI could help tackle the informational issue (improve the ability to locate data that respond to a specific need by using better search tools, powered by $\mathrm{AI}$ ); and b) blockchain (an Internet-based public ledger) may help strengthen appropriation (by tracing ownership and uses).

Government action here should be informed by a close monitoring of the changes induced by technology and the economy. Government might consider using data markets for public sector data; they might also ensure that the IP system is amenable to those transactions (see below). Government is also responsible for handling certain non-economic issues, such as privacy and integrity; if these are not appropriately addressed they will block transactions (which require reliability and trust).

Fourth, regarding personal data, the current "deal" implemented by online service providers is that users get free services in exchange for their personal data and behaviour on platforms. Questions have been raised regarding the fairness of this deal and its efficiency, and proposals have been made for individuals to own (and possibly sell) their personal data. Currently such data are proprietary - controlled by the host site - and are sometimes sold to third parties (for advertising, etc.).

\subsection{Adapt research and innovation support instruments}

Specific directions of change for innovation and research instruments that arise from the characterisation provided in the previous sections include 1) ensuring the responsiveness and agility of innovation policies, 2) ensuring there are instruments to support service innovation, and 3) adjusting the patent and IP system to the digital economy.

\section{Ensure the responsiveness and agility of policies}

The new instruments needed for the digital age should be quick and agile. Government needs to become more flexible and reactive, while keeping (prudential) rules of engagement when it comes to specific policy instruments, as the innovation agenda is shifting very quickly and is impossible to predict in certain fields.

Approaches to ensure rapid and agile policy responsiveness include the following:

- Policy experiments are needed that operate in a "start-up mode", whereby experiments can be deployed and then evaluated and modified, scaled up or down, or abandoned quickly. Implementing various alternative policy approaches on a small scale and combining them with close and frequent monitoring to identify what works and what does not also helps learning. 
- The use of digital tools to design innovation policy and monitor policy targets can help make decision making more quick and effective, on the basis of stronger evidence. For example, semantic analysis can support innovation policy making by exploring large quantities of text data (e.g. innovation policy documents, patents, scientific articles) to identify policy trends and anticipate emerging technology trends [see examples discussed at a recent workshop in OECD (2018c)].

- Another option, and one that avoids making technology choices, consists in shifting more support to instruments that do not target a specific technology. Such instruments include tax reliefs, certain regulations, and IP rights. The drawbacks of such instruments as compared with targeted ones (e.g. lack of selectivity resulting in a deadweight loss) of course need to be taken into account and weighted against the advantage of greater flexibility.

- Accelerating the procedures for application-based innovation support instruments also helps increase the responsiveness of these policy instruments. For example, the Pass French Tech programme offers start-ups in a hyper-growth stage with simplified and quick access to services (e.g. in the fields of financing, access to new markets, innovation, business development) to help them with their expansion (La FrenchTech, 2018).

- In fast-changing contexts, avoiding support of obsolete technologies and innovations based on them may require more reliance on innovators than on government decisions. Providing autonomy and agility to the avenues that are pursued to achieve a stated policy objective - as is characteristic of the Defense Advanced Research Projects Agency (DARPA) (in the United States) - is one option. The emphasis here is set on the intended outcomes rather than the specific technologies to achieve solutions.

- Where making choices on specific technologies cannot, however, be avoided - as for instance with public procurement involving specific requirements such as data security - designing public institutions connected to technology developments in the private sectors can prove useful. Data61 in Australia and Digital Catapult in the United Kingdom are examples.

- Regulation that sets standards also needs to be agile, to allow for innovations while avoiding detrimental effects. This is especially important given that the various types of problems raised by new products (e.g. regarding safety or security) are often difficult to anticipate before their commercialisation. According to some, fast-paced technical change requires outcomes-focused regulation. That is to say, there is no prescription of what is and what is not allowed, but rather the desired outcomes and main principles are being established in order to prevent public harm - so-called "anticipatory regulation". This approach requires scanning future potential threats and risks around a new technology or activity, as performed by the UK Food Standards Agency and the UK Human Fertilisation and Embryology Authority (Armstrong and Rae, 2017).

\section{Support service innovation that implements digital technologies}

Supporting services innovation requires using innovation support instruments different from those commonly used. Many innovation policies have been conceived for manufacturing types of innovations, which are intensive in $R \& D$, result in patents, etc. Service-type innovation (e.g. new business models) relies very little on R\&D, and thus may not be eligible to policy support (e.g. R\&D tax incentives). However, service innovation requires the business to have a deep understanding of digital technologies that is not yet 
widespread, especially among SMEs in non-digital industries. The appropriability of service innovation is also limited, as few or no intellectual property rights [IPR] can be applied. A degree of support targeted to innovators in these sectors might be warranted.

\section{Adapting the IP system}

The IP system is aimed at encouraging the creation of new ideas, be they technological or commercial. The current system has been designed for tangible inventions, embodied in physical products and processes. With digitalisation, it is confronted with new challenges. These include in particular the following:

- Data (including software) are the main input and output of digital innovation. Open access to data, unhindered in view of DNR, is often optimal for society. Incentives to produce data in the first place need to be taken into account; these may call for some exclusivity, but the pressure to open access to data will increase. The question is how the IP system should adapt.

- AI can create patentable inventions. This raises the question: who should own them, between the original programmer, the user of the software that generated the invention, and the owners of the data to which $\mathrm{AI}$ is applied? In addition, patent grants require that the invention be "non-obvious to a person skilled in the art". If an AI system is considered to be such a person skilled in the art, this might put the bar much higher for patentability in certain domains (e.g. combinatorial chemistry) where AI is now a major research tool.

- The ease of diffusion of such products makes the counterfeiting of the intangible component of products easy. Certain developments, such as 3D printing, may allow for new forms of manufacturing, weakening the protection of IP. On the other hand, digital technologies such as blockchain can facilitate enforcement of IP by making it possible to trace the uses of particular data files, and so limit online counterfeiting. Blockchainenhanced intellectual property on a range of intangibles (such as photographs, music, movies, etc.) may be a new way forward to create a different type of IP for the intangible economy - one that would be more easily enforceable and tradeable (as blockchain makes all uses identifiable and traceable).

- IP rights and patents in particular may become much less relevant and weaken the incentives they provide in this new environment. With digital innovation, what matters is control of standards and of data. Trademarks may, however, take on renewed importance as anchors for online search (Bechtold and Tucker, 2014).

\section{Supporting the development of generic digital technologies}

Policy should support the development of core, generic (or multi-purpose) digital technologies with a view to facilitating downstream innovation and to address societal challenges. At the moment businesses are investing heavily in digital technologies. However, when looking back at the history of these technologies, initial developments were most often sponsored by government. The Internet is often cited as such an example, but this is also the case for AI, which was developed almost exclusively through publicly funded research over more than five decades before it was seized on by businesses in the late 2000s. Hence government needs to keep investing in core technologies so as to prepare future waves of innovations; but it also needs to ensure that the development of multipurpose digital technologies does not serve exclusively commercial purposes but also social and environmental ones. In many cases, public research is the best placed to do just 
that. Those investments benefit from collaboration in technology development and around AI's economic, ethical, policy and legal implications. AI is expected to transform economic activity; it already raises complex societal and ethical issues. The transformation may however take some time, as the range of possible applications goes far beyond current ones (Brynjolfsson, Rock and Syverson, 2017). While recent research suggests that the productivity of innovative activities has been subject to decreasing returns over the past few decades (Bloom et al., 2017), some scholars expect AI to possibly reverse this trend (Cockburn, Henderson and Stern, 2018). Special attention also needs to be paid to the development of applications that allow wider adoption and diffusion to the economy at large, including SMEs.

\subsection{Support competition and collaboration}

\section{Support competition}

As is well known, innovation requires rents to incentivise would-be innovators to invest. At the same time, as a threat to businesses that stand still, competition is needed to spur innovation, but it reduces rents. With the digital transformation, the dynamics of innovation rents may be changing. Knowledge spillovers might increase in size and speed with digitalisation (and globalisation); certainly the channels for knowledge circulation are changing (with the Internet and platforms). Market applications from any piece of knowledge are larger and quicker, and there are possibilities for successful innovations to reach a large market, which is good for society and investment; but the period and scope for appropriability (private rate of return) might be reduced and the risk of not reaping returns may increase, which may deter investment. The fluidity ("frictionlessness") of data translates into fluidity of digital innovation-based rents.

There is therefore a need to review competition policies for innovation in the digital context. There are various questions around the use of data as a source of market power. Another question concerns the degree of contestability of markets for digital innovation, as these markets are subject both to rapid innovation (a source of contestability) and various sorts of scale economies (a source of persistent concentration). Dialogue between competition authorities and innovation policy makers will be important here, to take stock of the specific innovation context of the digital economy. As competition on digital markets takes place at a global level, there may also be a need for greater co-operation across jurisdictions.

Competition is not just affected by competition policies; a number of policy instruments, such as public R\&D or IPR, may have an asymmetric impact on market players. While such instruments are accessible to all in principle, this may not be the case in practice, e.g. as regards the capacity of firms to defend their IP rights in courts, to co-operate effectively with public labs, or to access public procurement. Thus, considerations of how policies can best support entrepreneurship and entry will also be important.

\section{Support SMEs}

For any firm, adapting to digitalisation means much more than simply purchasing new computers and software: it is about changing business processes, and often business models. Changing business models is difficult. Just designing or even identifying a new business model requires strategic capabilities; the new business model may require in-depth and broad change in the company, and new skills and capital. It is also risky - the attempt may well fail. This might be less of a problem for large firms, which are active in various 
business lines and if failing in one they can compensate in others (although the Nokia case shows that failure can be fatal even to a large firm). But for small firms it is vital, and the stakes can deter SMEs from transition to digital (notwithstanding the start-ups which are "born digital"). The disappearance of many SMEs that fail to digitalise would mean the loss of much industry and market-specific know-how, which constitutes unique intangible capital. According to endogenous growth theory (Aghion and Howitt, 1992), creative destruction can be excessive, resulting in the destruction of useful capital. It is therefore in the public interest to provide selective support to the adaptation of SMEs, while of course not hampering the competitive process to work so that the less performing ones are not saved.

Thus, there is a possible role for government in providing various types of support to SMEs to facilitate their adoption of digital technologies, for example in terms of expertise (to develop new skills and support capacity building) and financing (e.g. loan guarantees). In Germany an integrated policy package has been put together to facilitate the digital transition of SMEs, with a focus on providing them with expertise; it includes measures such as competence centres and individual counselling services to support adoption and diffusion. Germany's Industry 4.0 Competence Centres are an example.

\section{Support all regions}

The skewed distribution of performance and rewards across regions and cities raises issues of equity (rising inequality) and of efficiency (reduced diversity). "Excellence-based policies", even if blind to location, tend to favour geographical concentration since excellence is concentrated (due notably to knowledge spillovers). There is then the risk of a widening gap between leading and lagging regions. Excellence-based policies should therefore be complemented by policies favouring geographical inclusiveness and diversity. The focus should be on local development, making use of local knowledge and other specificities (e.g. the Smart Specialisation approach in the EU, whereby regional research and innovation strategies are developed building on specific regional strengths and comparative assets). This might be at the cost of short-term, country-level industrial and scientific efficiency, but it might also serve 1) longer-term efficiency, as diversity is a factor of discoveries and innovation, and the full exploitation of all types of talent benefits all of society; and 2) a broader vision of efficiency, integrating all sorts of costs related to migration, urbanisation, etc.

\section{Foster interactive and collaborative innovation}

As innovation increasingly involves inter-firm collaboration and collaboration with universities, research institutions and in some cases individual inventors, government policy will have to continue forming innovative eco-systems as the most effective organised entities for developing new technology.

In many countries, there are already special instruments to encourage industry collaboration (conditional grants, etc.). Governments have also funded industry-level support programmes (e.g. the Dutch Top sectors), which include developing a strategic vision, investing in technology upstream, and encouraging co-operation between firms. This is not specific to digital innovation, but collaboration is taking on greater importance in a digital context. Government might think of moving more of its support to developing linkages between firms while avoiding collusion between players, as collusion would hamper new entry. 
Knowledge intermediaries such as Fraunhofer in Germany or Catapult Centres in the United Kingdom also have an important role to play in facilitating interactive and collective innovation in the digital age. This is because a great deal of knowledge cannot be transmitted as ready-made over the Internet but instead requires significant adaptation to each specific application. This is the case for instance with AI. Implementing AI requires strong capabilities; and knowledge about applying AI is not easy to transmit as it is very specific (i.e. knowledge extracted from one data set does not usually apply to another one). This non-codified knowledge is strongly complementary to the codified sort. Hence individuals, businesses or places that possess such knowledge are at an advantage vis-à-vis others.

There have been several policy initiatives to support collaborative innovation. An example is the Dutch HTSM Roadmap Automotive 2018-2025, developed in collaboration among industry, research institutes and government. The roadmap identifies medium-term industry needs and sets research and innovation priorities in the fields of green and smart mobility (e.g. assisted and automated driving, connectivity, smart mobility services). It highlights the importance of cross-sectoral co-operation (e.g. with the fields of photonics, semiconductors, high-tech materials) and collaboration with international partners. Similar strategies have been adopted by many other European research agendas and priorities, such as those of the European Road Transport Research Advisory Council (ERTRAC), the European Council for Automotive R\&D (EUCAR), the European Platform on Smart Systems Integration (EPoSS), and the European Automotive Research Partners Association (Wouters et al., 2017).

\subsection{Optimise the efficiency of public research}

To the same extent that digital technologies promise to increase the efficiency of innovative activities, they also offer to increase research efficiency in various ways. The most noted potential, one that applies across all disciplines including the humanities, consists in exploiting data and machine learning techniques to support the research process. Other avenues include the involvement of non-experts in the research process ("citizen science"), including by "gamification" of research challenges: attracting crowds of amateurs to try different combinations (see e.g. the famous "Foldit" game, which consists in predicting the structure of proteins). Researchers from academia are increasingly adopting these new approaches, enabled by the Internet and other information technologies.

Avenues for preparing public research include the following four domains:

1. Fostering interdisciplinarity (particularly combining computer sciences with specific traditional disciplines). For instance, many universities currently offer interdisciplinary undergraduate degrees with a digital component (e.g. MIT undergraduate degrees on computer science and biology, and on computer science, economics and data science) (MIT, 2018).

2. Offering specific training and capacity-building activities for scientists to master digital tools (data curation, simulation, deep learning, etc.), so that even if a particular scientist does not apply digital tools personally, they should be able to collaborate with team members who are applying such tools. Strengthening researchers' digital skills is one of the key objectives of the digitalisation strategy for the higher education sector in Norway (2017-21) (Government of Norway, 2018). 
3. Developing digital tools and infrastructures that may be the critical for research and that require new investments (e.g. platforms for sharing data, supercomputing facilities for AI, etc.). An example is the High Performance Computing Infrastructure (HPCI) programme in Japan, which involves an annual investment of more than USD 120 million to build a high-performance computing infrastructure that is accessible to universities and public research centres for R\&D purposes in a range of fields.

4. Engaging in partnerships and creating "spaces" for co-creation with industry to draw on industry progress in advanced digital technologies for their applications to research, and on capacities in industry and science, moving knowledge transfer from science to industry or vice versa.

\subsection{Education and training: Implications for innovation authorities}

Preparing individuals for the digital transformation is of course essential, to increase the pool of skilled workers and empower their participation. The policy domain is critical to innovation but is of course far broader, touching on many other dimensions. The OECDwide Going Digital project looks into this question in depth [see OECD (2017c) and Nedelkoska and Quintini (2018)].

It is important that innovation authorities collaborate with those in charge of education and labour market policies, to ensure that the particular skills needed for digital innovation are being developed. Innovation authorities have an important role to play in informing other government authorities about new skill demands by industry they see that arise with rapid and broad technology change. Often combinations skills are required by industry, for example, innovation in the automotive industry increasingly requires strong capabilities in software engineering and AI, in addition to traditional core competences in mechanical and electronic engineering. An example of a co-ordinated approach is the National Initiative on Digital Competences 2030 in Portugal (INCoDe.2030), which for instance aims to meet three main challenges: generalise digital literacy to ensure social inclusion; stimulate employability and professional specialisation in digital technologies; and enhance the production of new knowledge in digital areas (FCT, 2018).

For innovation authorities, it is also important to support training and education for managerial skills in firms that enable innovation. There is strong evidence of the importance of management skills for firm performance. This is even more important in a context of disruptive technological change (Bloom and van Reenen, 2007).

Innovation policies can also offer opportunities for individuals to participate in innovation activities. Some groups have traditionally been underrepresented in research and innovation activities (e.g. women, ethnic minorities, residents in deprived areas). With digital transformation, diverse skills and profiles are needed, and drawing on the potential of these groups will be all the more important. Policy instruments to address social inclusiveness challenges include those aimed at building capacities (e.g. entrepreneurship education); at addressing discrimination and stereotypes (e.g. awareness-raising activities, role models and mentoring programmes); and at addressing barriers to entrepreneurship faced by disadvantaged groups (e.g. facilitating access to finance through microcredit or equity financing, providing tailored business development support, and promoting their insertion in business and research networks, for instance through the provision of innovation vouchers). Some countries have already implemented "inclusive innovation policies". Examples include targeted grants for research projects led by researchers from 
disadvantaged groups in South Africa; a programme to improve the research environment for women in Japan; and initiatives to support entrepreneurship by minority communities in Israel. Planes-Satorra and Paunov (2017) provides more inclusive innovation policy examples.

\subsection{New challenges to innovation policy making}

\section{Set national policies in a context of global markets}

Fluidity makes data ubiquitous entities that ignore distance and national boundaries. Hence digital innovation is global in reach and potential impact. There are important consumer/producer gains from serving global markets, with scale economies and network benefits from digital innovations that naturally extend beyond national boundaries, including the lower unit cost of serving a larger (international) market.

That raises a challenge for national policy makers: How can they ensure that their own citizens (and taxpayers) benefit from national policies, and that most of the benefits (e.g. income generated, productivity gains or job creations) do not leak abroad? The question has been raised in the past, in the context of basic research funding and business R\&D support measures, as to whether a country's benefits (jobs, knowledge, revenue, taxes, etc.) might flow to other countries. Cases of successful start-ups having benefited from government support then being acquired by foreign multinationals have raised questions about the location of the benefits arising from these start-ups. Along the same lines, there are questions about the sharing of benefits generated by exploitation of national data (e.g. from the public health system) with foreign multinationals. The embodiment of value in intangible assets (intellectual property), the intangible character of digital products transacted across borders, and the prevalence of electronic payments all facilitate the circulation of revenue, which can end up in tax havens. How government will address the issue of territoriality will have a strong influence on the efficiency of policies, but also on their legitimacy. Co-operative solutions will be needed that allow a sharing between countries of the benefits arising from international flows of data and knowledge linked to national policies. The OECD activity on base erosion and profit shifting (BEPS) is a step in this direction. Under this inclusive framework, over 100 countries and jurisdictions are collaborating to implement the BEPS measures and tackle BEPS (www.oecd.org/tax/beps/).

\section{Engaging with the public}

The digital transformation has captured much attention in the press and with the public sometimes with negative views, notably but not only in Europe (having to do with leakages of personal data, the threat of robots taking over jobs, or restricted access to certain public data) (Figure 1). This distrust vis-à-vis a new technology has happened before, for instance with genetically modified organisms and with nanotechnology. It is therefore important that all actors, notably government, engage with all stakeholders, showing the beneficial aspects of these technologies and addressing the concerns (e.g. privacy). The risk of not engaging is to be confronted at some point in the future with a significant backlash, with potentially negative impacts on the development and deployment of these technologies. 


\section{Figure 1. Public opinion on the future impact of robots and AI on jobs in the EU}

Percentage of respondents agreeing and disagreeing with the statement "Due to the use of robots and artificial intelligence, more jobs will disappear than new jobs will be created?"

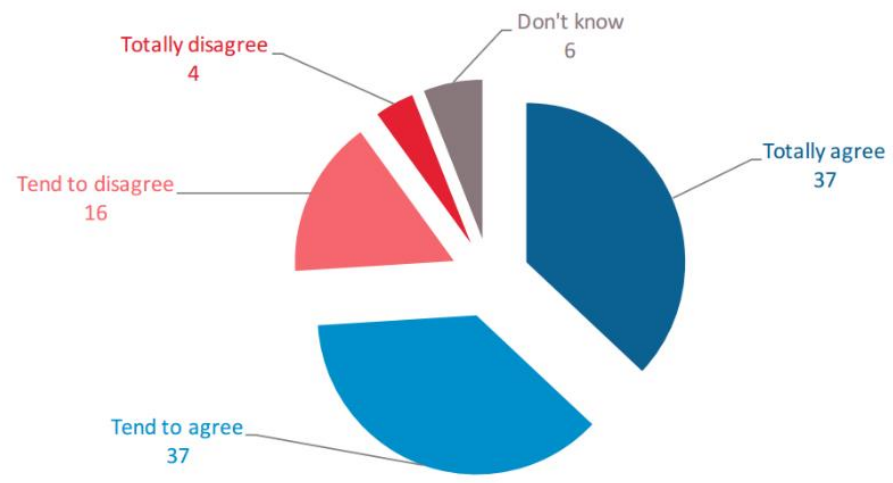

Note: Based on 27901 responses to a survey carried out in the 28 EU member states in March 2017. Source: European Commission (2017).

\section{Ensuring government access to skills and data}

A number of challenges arise, notably in the field of AI where substantial investments (about USD 40 billion in 2016 world wide and much more according to some estimates) are mostly undertaken by business. Salaries for experts in AI are so high that government and academia cannot afford them. Top-level scientists work with businesses, keeping a link with academia mainly for accessing and hiring students. Even basic research on AI is currently largely done by businesses, as noted in articles published in prestigious scientific journals, like Nature and Science. While government funding has been supporting AI research for decades and is at the root of recent successes, funding is now largely undertaken by businesses as governments can ill afford the huge costs of research and retaining the top researchers. The fact that businesses are active in the field is certainly positive, but government's weakening position raises important issues. Who will fund the basic research needed to sustain progress in the field, as there are limits to the willingness of businesses to generate spillovers that also serve their competitors? How can government design and monitor the implementation of societal principles (regarding ethics, accountability, etc.) if it cannot hire top-level experts?

The concern over government's access to skills may well extend beyond research. Not only development of specific applications of public interest), but also the design of regulation and policies requires an in-depth understanding of the technologies at stake. The concern might also extend beyond access to skills, and include access to data and information systems. A large share of data relevant to innovation policies is in private hands, and datagathering infrastructures are increasingly based on the Internet and controlled by businesses. This is the case for instance with the databases of scientific publications, used to compile indicators that feed into the monitoring and policy processes. The risk, if such knowledge cannot be mobilised, is that government either might abstain from playing its role, or could design inappropriate rules and policies.

It is vital that government keep its ability to act, and to act in an independent way. For that, it needs to ensure that there are enough workers with high-level skills in digital technologies, notably AI, so that these workers' wages remain affordable to the public sector. Government also needs to consider practical ways of ensuring access to data that is essential to regulation and policy making. 


\section{Conclusion}

Digitalisation is changing many of the economic mechanisms that drive innovation, reflecting the current fluidity of data. Innovation policies should adapt by changing their targets and modus operandi. In fact, a number of countries have begun to adapt and experiment already.

As data have become a major input to innovation, policies that affect access to data have become an essential component of the innovation policy mix (interoperability, intellectual property, etc.). With more collaboration in innovation, it often makes more sense for policies to favour ecosystems rather than individual firms. Servitisation calls for broadening policies supporting $R \& D$ - service innovation is often not based on $R \& D$ at all. Policies also need to allow for entrepreneurship, creating conditions for the digital age that can involve all firms, regions and individuals.

Correcting when needed for the skewed distribution of performance and rewards while maintaining market incentives to innovate is not a new trade-off, but it is made more prominent with the digital transformation, and may need to be addressed in new ways. Policies need to become more agile and responsive to rapid changes, as many new developments are in flux and require further monitoring and fast adjustments. Digital technologies can facilitate the design, implementation, monitoring and evaluation of policies through the use of databases, data analytics, real-time monitoring, etc.

A major question for the future is whether $\mathrm{AI}$ is distinctive from other digital technologies in its implications. For policies, AI will mark a further stage in the digitalisation process, allowing the digitisation of tasks that until now were the preserve of humans (predictive analytics, medical diagnosis, driving, etc.). In fact, all challenges identified here also apply to AI, and most of them are even magnified. With AI it is not only data but also knowledge that becomes fluid. Overall, innovation policies are at a crossroads, and more experiments are needed in order to identify the best ways to adapt them in this new landscape. 


\section{References}

Aghion, P. and P. Howitt (1992), "A Model of Growth Through Creative Destruction", Econometrica, Vol. 60/2, pp. 323-351, http://dx.doi.org/10.3386/w3223.

Armstrong, H. and J. Rae (2017), A working model for anticipatory regulation, NESTA, https://media.nesta.org.uk/documents/working_model_for_anticipatory_regulation_0.pdf.

Autor, D. et al. (2017), "Concentrating on the Fall of the Labor Share", American Economic Review, Vol. 107/5, pp. 180-185, http://dx.doi.org/10.1257/aer.p20171102.

Bar-Isaac, H., G. Caruana and V. Cuñat (2012), "Search, Design, and Market Structure", American Economic Review, Vol. 102/2, pp. 1140-1160, http://dx.doi.org/10.1257/aer.102.2.1140.

Bechtold, S. and C. Tucker (2014), "Trademarks, Triggers, and Online Search", Journal of Empirical Legal Studies, Vol. Forthcoming, http://dx.doi.org/10.2139/ssrn.2266945.

Bloom, N. et al. (2017), “Are Ideas Getting Harder to Find?”, NBER Working Paper, No. 23782, National Bureau of Economic Research, Cambridge, MA, http://dx.doi.org/10.3386/w23782.

Bloom, N. and J. van Reenen (2007), "Measuring and Explaining Management Practices across Firms and Countries", The Quarterly Journal of Economics, Vol. 122/4, pp. 1351-1408, http://dx.doi.org/10.2307/25098879.

Board of Innovation (2018), Open Innovation and Crowdsourcing Resources, https://www.boardofinnovation.com/list-open-innovation-crowdsourcing-examples/ (accessed on 12 April 2018).

Brynjolfsson, E., F. Eggers and A. Gannamaneni (2018), "Using Massive Online Choice Experiments to Measure Changes in Well-being", NBER Working Paper, No. 24514, National Bureau of Economic Research, Cambridge, MA, http://dx.doi.org/10.3386/w24514.

Brynjolfsson, E., X. Hui and M. Liu (2018), "Does Machine Translation Affect International Trade? Evidence from a Large Digital Platform", NBER Working Papers, No. 24917, National Bureau of Economic Research, Cambridge, MA, http://dx.doi.org/10.3386/w24917.

Brynjolfsson, E., Y. Hu and M. Smith (2010), "Research Commentary: Long Tails vs. Superstars: The Effect of Information Technology on Product Variety and Sales Concentration Patterns", Information Systems Research, Vol. 21/4, pp. 736-747, http://dx.doi.org/10.1287/isre.1100.0325.

Brynjolfsson, E. and A. McAfee (2017), "The Business of Artificial Intelligence: What it can and cannot do for your organization", Harvard Business Review, Vol. July 2017, https://hbr.org/coverstory/2017/07/the-business-of-artificial-intelligence.

Brynjolfsson, E. and T. Mitchell (2017), "What can machine learning do? Workforce implications", Science, Vol. 358/6370, pp. 1530-1534, http://dx.doi.org/10.1126/science.aap8062. 
Brynjolfsson, E., D. Rock and C. Syverson (2017), “Artificial Intelligence and the Modern Productivity Paradox: A Clash of Expectations and Statistics", NBER Working Paper, No. 24001, National Bureau of Economic Research, Cambridge, MA, http://dx.doi.org/10.3386/w24001.

Catalini, C. and J. Gans (2018), "Initial Coin Offerings and the Value of Crypto Tokens", NBER Working Paper, No. 24418, National Bureau of Economic Research, Cambridge, MA, http://dx.doi.org/10.3386/w24418.

Catalini, C. and J. Gans (2016), "Some Simple Economics of the Blockchain", NBER Working Paper, No. 22952, National Bureau of Economic Research, Cambridge, MA, http://dx.doi.org/10.3386/w22952.

CB Insights (2017), Amazon Puts Fast Fashion In The Crosshairs With New Patent, CB Insights Research Results, https://www.cbinsights.com/research/amazon-fashion-apparel-manufacturingpatent/ (accessed on 01 June 2018).

Cockburn, I., R. Henderson and S. Stern (2018), “The Impact of Artificial Intelligence on Innovation”, NBER Working Paper, No. 24449, National Bureau of Economic Research, Cambridge, MA, http://dx.doi.org/10.3386/w24449.

Dai, Q., E. Shin and C. Smith (2018), "Open and inclusive collaboration in science: A framework", OECD Science, Technology and Industry Working Papers, No. 2018/07, OECD Publishing, Paris, http://dx.doi.org/10.1787/2dbff737-en.

Data61 (2018), About D61+ Expert Connect, https://expertconnect.global/about (accessed on 29 May 2018).

Data61 (forthcoming), CSIRO's Data61: Country case study contribution to the OECD TIP Digital and Open Innovation project.

Deichmann, J. et al. (2016), Creating a successful Internet of Things data marketplace, McKinsey, https://www.mckinsey.com/business-functions/digital-mckinsey/our-insights/creating-a-successfulinternet-of-things-data-marketplace.

European Commission (2017), Special Eurobarometer 460 - Attitudes towards the impact of digitisation and automation on daily life, Survey requested by the European Commission, Directorate-General for Communications Networks, Content and Technology and co-ordinated by the Directorate-General for Communication, http://ec.europa.eu/commfrontoffice/publicopinion/index.cfm/Survey/getSurveyDetail/instruments/S PECIAL/surveyKy/2160 (accessed on 25 May 2018).

Ezoic (2018), Ad Testing and Site Optimization, https://www.ezoic.com/ad-testing/ (accessed on 03 October 2018).

FCT (2018), The INCoDe.2030, Fundação para a Ciência e a Tecnologia, http://www.incode2030.gov.pt/en/initiative (accessed on 29 May 2018).

Garicano, L. and E. Rossi-Hansberg (2006), "Organization and Inequality in a Knowledge Economy", The Quarterly Journal of Economics, Vol. 121/4, pp. 1383-1435, http://dx.doi.org/10.1093/qje/121.4.1383. 
Gaspar, J. and E. Glaeser (1998), "Information Technology and the Future of Cities", Journal of Urban Economics, Vol. 43/1, pp. 136-156, http://dx.doi.org/10.1006/JUEC.1996.2031.

Goldfarb, A. and C. Tucker (2017), "Digital Economics", NBER Working Paper, No. 23684, National Bureau of Economic Research, Cambridge, MA, http://dx.doi.org/10.3386/w23684.

Government of Norway (2018), Digitalisation strategy for the higher education sector 2017-2021, https://www.regjeringen.no/en/dokumenter/digitalisation-strategy-for-the-higher-education-sector2017-2021/id2571085/sec5 .

Haskel, J. and S. Westlake (2017), Capitalism without Capital : The Rise of the Intangible Economy, Princeton University Press, Princeton.

Kerr, W. and S. Kominers (2015), "Agglomerative forces and cluster shapes", The Review of Economics and Statistics, Vol. 97/4, pp. 877-899, http://dx.doi.org/10.1162/REST a 00471.

La FrenchTech (2018), Pass French Tech, http://www.lafrenchtech.com/en-action/pass-french-tech (accessed on 25 May 2018).

MIT (2018), Interdisciplinary Undergraduate Degrees \&lt; MIT, MIT Course Catalog - Bulletin 201718, http://catalog.mit.edu/interdisciplinary/undergraduate-programs/degrees/ (accessed on 29 May 2018).

Nedelkoska, L. and G. Quintini (2018), “Automation, skills use and training”, OECD Social, Employment and Migration Working Papers, No. 202, OECD Publishing, Paris, http://dx.doi.org/10.1787/2e2f4eea-en.

OECD (forthcoming), Vectors of the Digital Transformation, OECD, Paris.

OECD (2018a), Going Digital in a Multilateral World, Meeting of the OECD Council at Ministerial Level, Paris, 30-31 May 2018, http://www.oecd.org/mcm/documents/C-MIN-2018-6-EN.pdf (accessed on 04 June 2018).

OECD (2018b), Rethinking Antitrust Tools for Multi-Sided Platforms, http://www.oecd.org/competition/rethinking-antitrust-tools-for-multi-sided-platforms.htm (accessed on 24 September 2018).

OECD (2018c), Workshop on semantic analysis for innovation policy - Summary of discussions, Paris, 12-13 March 2018, Innovation Policy Platform, https://www.innovationpolicyplatform.org/semantics (accessed on 04 October 2018).

OECD (2017a), Going Digital: Making the Transformation Work for Growth and Well-Being, Meeting of the OECD Council at Ministerial Level, Paris, 7-8 June 2017, https://www.oecd.org/mcm/documents/C-MIN-2017-4\%20EN.pdf.

OECD (2017b), Algorithms and Collusion: Competition Policy in the Digital Age, http://www.oecd.org/daf/competition/Algorithms-and-colllusion-competition-policy-in-the-digitalage.pdf (accessed on 24 September 2018). 
OECD (2017c), Future of work and skills - Paper presented at the 2nd Meeting of the G20 Employment Working Group, http://www.oecd.org/els/emp/wcms_556984.pdf

OECD (2016a), Big Data: Bringing Competition Policy to the Digital Era, http://www.oecd.org/daf/competition/big-data-bringing.

OECD (2016), The Productivity-Inclusiveness Nexus: Preliminary version, OECD Publishing, Paris, http://dx.doi.org/10.1787/9789264258303-en.

OECD (2015a), Data-Driven Innovation: Big Data for Growth and Well-Being, OECD Publishing, Paris, http://dx.doi.org/10.1787/9789264229358-en.

OECD (2015b), The Innovation Imperative: Contributing to Productivity, Growth and Well-Being, OECD Publishing, Paris, http://dx.doi.org/10.1787/9789264239814-en.

OECD (2015c), "Making Open Science a Reality", OECD Science, Technology and Industry Policy Papers, No. 25, OECD Publishing, Paris, http://dx.doi.org/10.1787/5jrs2f963zs1-en.

OECD (2013), Supporting Investment in Knowledge Capital, Growth and Innovation, OECD Publishing, Paris, http://dx.doi.org/10.1787/9789264193307-en.

Paunov, C. and S. Planes-Satorra (forthcoming), "The impacts of digital transformation on innovation across sectors (working title)”, OECD Science, Technology and Industry Policy Papers, OECD Publishing, Paris..

Planes-Satorra, S. and C. Paunov (2017), "Inclusive innovation policies: Lessons from international case studies", OECD Science, Technology and Industry Working Papers, No. 2017/2, OECD Publishing, Paris, http://dx.doi.org/10.1787/a09a3a5d-en.

Romer, P. (1990), "Endogenous Technological Change", Journal of Political Economy, Vol. 98/5, pp. 71-102, https://ideas.repec.org/a/ucp/jpolec/v98y1990i5ps71-102.html (accessed on 11 October 2018).

Sheehan, J. (2018), Digital Health Innovation:Policy and Standards, Presentation to the OECD Digital Health Innovations workshop, 12 April 2018, the Hague, https://www.innovationpolicyplatform.org/system/files/Panel\%201.5.\%20Sheehan.pdf (accessed on 01 June 2018).

Thomson, J. (2018), What Amazon's Private Label Business Means for Retailers, Total Retail, http://www.mytotalretail.com/article/what-amazons-private-label-business-means-for-retailers/ (accessed on 17 April 2018).

TransportAPI (2018), Transport API - the digital platform for transport, https://www.transportapi.com/ (accessed on 30 May 2018).

Weins, K. (2017), Cloud pricing comparison: AWS vs. Microsoft Azure vs. Google vs. IBM| InfoWorld, InfoWorld, https://www.infoworld.com/article/3237566/cloud-computing/cloud-pricingcomparison-aws-vs-azure-vs-google-vs-ibm.html (accessed on 31 May 2018). 
Wouters, J. et al. (2017), HTSM Roadmap Automotive 2018-2025 | Dutch Mobility Innovations, https://dutchmobilityinnovations.com/spaces/86/dutch-mobilityinnovations/articles/news/19149/roadmap-automotive-2018-2025 (accessed on 31 May 2018).

Yanagisawa, T. and D. Guellec (2009), "The Emerging Patent Marketplace", OECD Science, Technology and Industry Working Papers, No. 2009/9, OECD Publishing, Paris, http://dx.doi.org/10.1787/218413152254. 